\title{
Ontogeny of the Electric Organs in the Electric Eel, Electrophorus electricus: Physiological, Histological, and Fine Structural Investigations
}

\author{
Horst O. Schwassmann ${ }^{a}$ M. Ivaneide S. Assunção ${ }^{b}$ Frank Kirschbaum ${ }^{c, d}$

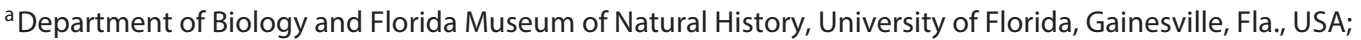 \\ ${ }^{b}$ Department of Zoology, Museu Paraense E. Goeldi, Belém, Brazil; ' Leibniz Institute of Freshwater Ecology and \\ Inland Fisheries, and ${ }^{d}$ Faculty of Agriculture and Horticulture, Humboldt University, Berlin, Germany
}

\section{Key Words}

Electric eel · Electric organs · Electric organ discharge development · Electrocyte development · Electromatrix . Electrocyte ultrastructure

\begin{abstract}
This study attempts to clarify the controversy regarding the ontogenetic origin of the main organ electrocytes in the electric eel, Electrophorus electricus. The dispute was between an earlier claimed origin from a skeletal muscle precursor [Fritsch, 1881], or from a distinct electrocyte-generating matrix, or germinative zone [Keynes, 1961]. We demonstrate electrocyte formation from a metamerically organized group of pre-electroblasts, splitting off the ventralmost tip of the embryonic trunk mesoderm at the moment of hatching from the egg. We show details of successive stages in the development of rows of electric plates, the electrocytes, by means of conventional histology and electron microscopy. The membrane-bound pre-electroblasts multiply rapidly and then undergo a specific mitosis where they lose their membranes and begin extensive cytoplasm production as electroblasts. Electrical activity, consisting of single and multiple pulses, was noticed in seven-day-old larvae that began to exhibit swimming movements. A separation of discharges into single pulses and trains of higher voltage pulses was seen first
\end{abstract}

\section{KARGER}

E-Mail karger@karger.com

www.karger.com/bbe in 45-mm-long larvae. A lateralis imus muscle and anal fin ray muscles, implicated by earlier investigators in the formation of electrocytes, begin developing at a time in larval life when eight columns of electrocytes are already present. Axonal innervation is seen very early during electrocyte formation.

(c) 2014 S. Karger AG, Basel

\section{Introduction}

The presence of electric organs in a few but widely different groups of (marine and fresh water) fishes had posed an early problem for Darwin's concept of evolution by natural selection. More than 150 years of research could now resolve the early difficulties. It was already in 1881 that Dubois-Raymond [in Sachs, 1881] not only hinted at a possible 'sensory function' but also proposed the 'pseudo-electric organs' as phylogenetic forerunners of 'complete electric organs', as in the electric eel. On the same page, he shows the drawing by Sachs of the electric organ of Sternopygus virescens. It is apparently Eigenmannia virescens. Today, an extensive body of knowledge exists about the electrosensory and electrocommunicative aspects in the weakly electric Gymnotiformes.

The commonly held notion of skeletal muscle origin of the eel's electric organs can be traced to Fritsch [1881], (c) 2014 S. Karger AG, Basel

0006-8977/14/0844-0288\$39.50/0 
who specified the lateralis imus muscle, the 'Zwischenmuskel' of Valentin [1842], as the source of the main organ's electroplates, while Hunter's organ should be formed, according to Fritsch [1881], by inner anal fin ray muscles. His hypothesis was rendered questionable by Keynes' [1961] demonstration of a 'germinative region' of presumed electroblasts in a 12-cm-long eel, implying a process of direct formation of electrocytes without skeletal muscle intermediaries. Several studies found evidence of remains of cross-striated tissue elements in presumably early stages of electrocyte formation; evidence that seemed to support the notion of myogenic origin [Wachtel, 1964; Szabo, 1966; Esquibel et al., 1971]. Other reports, as the one by Machado et al. [1976], failed to detect such organized myofibrillar structures in electrocytes of slightly larger specimens. Szabo [1966] attempted to combine the two apparently opposing hypotheses of main organ electrocyte origin by accepting the germinative region of Keynes as source of early formation of units which would then pass through an intermediate skeletal muscle phase, leaving behind some organized myofibrillar elements. He also stressed the need for obtaining embryonic material that would be necessary for elucidating the actual process of electrocyte formation [Szabo, 1966]. When laboratory breeding of the small gymnotiform $E$. virescens was accomplished [Kirschbaum, 1975, 1979], an ontogenetic succession of a larval electric organ and its replacement by the adult organ was demonstrated [Kirschbaum, 1977, 1983, 1995]. In the largest gymnotiform, the electric eel, the voluminous main organ would correspond to the larval organ, while Hunter's organ, which is ventral to the former and develops much later, would constitute the adult electric organ [Bass, 1987; Kirschbaum, 1995]. New ontogenetic material from field studies [Assunção and Schwassmann, 1995] and from dealer sources has enabled us to redescribe the ontogenetic sequence of the eel's electric organs, correlating it with data on electric organ discharge [Kirschbaum and Schwassmann, 2008]. This paper illustrates successive stages in electric organ development of Electrophorus electricus, as seen by behavioral, physiological, light-microscopic, and fine-structural techniques, beginning the day after hatching from the egg.

\section{Materials and Methods}

After finding spawning sites of E. electricus on Marajó Island in 1988 [Assunção and Schwassmann, 1995], embryos and young larvae were taken from nests and reared in captivity to study early development of electric organs and their innervation by histologi- cal methods. Part of the electrical and histological data utilized came from a group of 36 dark-pink larvae that had hatched from eggs in their nest November 21, 1988. These larvae were transferred nine days later to an aquarium when 16-18 $\mathrm{mm}$ long. Their developmental state would correspond to the end of the eleutheroembryonic phase of Balon [1975], when exogenous feeding is about to begin. They grew to a length of $65 \mathrm{~mm}$ in two months. Prior to fixing specimens for anatomical study, their electrical activity was monitored and photographed for later evaluation. During field work, we utilized a Tektronix 564 storage screen oscilloscope and a Nikon 35-mm camera. A gasoline-powered generator in the small fishing village Cachoeira do Ararí provided electrical power during late evening hours. A home-made 60-cycle T-notch filter was used mostly, except for the records from the smallest hatchlings. Specimens were placed in a plastic chamber inside which carbon rod electrodes led from near head and tail to the vertical amplifiers. The water was connected to ground, but no standardized recording conditions were possible due to the movements of the larvae. Prodding of the specimens by moving one of the electrodes was used frequently to elicit discharges.

A total of 24 embryos and larvae, $10-48 \mathrm{~mm}$ long, were fixed in buffered formalin (the larger ones cut into several pieces) and embedded in paraffin for serial sectioning at $8 \mu \mathrm{m}$, and every section was mounted. Fourteen were cut in the transverse plane, and four in parasagittal sections. Staining was by Alcian blue, followed by Harris' hematoxylin-eosin staining, a combination which permitted clear differentiation of categories of histological elements, especially muscle- and electrocyte-forming tissue. A few 1.0- $\mu \mathrm{m}$ thick sections in transverse and parasagittal planes were obtained from a $15-\mathrm{mm}$ specimen that was embedded in Spurr's [1969] Epon and stained with toluidine blue.

The larvae for the electron-microscopic study were taken from their foam nests on Marajó Island in November of 1991; they were $15-16 \mathrm{~mm}$ long and had hatched from their eggs six days earlier. They had their gas bladder and buccal cavity filled with air and showed oriented swimming movements, which corresponds to about the time of transition from the embryonic to the protopterygial larval phase. We had recorded early electrical activity from specimens of this age and size [Schwassmann and Assunção, 1989]. When examining these larvae with a magnifying glass, we could discern a row of ten to fifteen glassy bulges, pearl-like in appearance, in the mid section of the tail, which is often referred to as 'trunk'. A second thinner row was sometimes noted ventral to the former. These glassy compartments are the electrocytes of the first developing columns. Within a few hours, however, increasing skin pigmentation made further observation of the growing columns impossible in this manner. Three of these larvae were fixed by immersion in Trump's fixative [McDowell and Trump, 1976] after having been cut into three pieces each. They were kept at ambient temperature in the field $\left(24-27^{\circ} \mathrm{C}\right)$, transferred three weeks later to $70 \%$ ethanol, and kept refrigerated until January 1992 when they were processed by washing in $0.1 \mathrm{M}$ cacodylate buffer at $7.2 \mathrm{pH}$, postfixed with $1 \%$ osmium tetroxide in cacodylate buffer for one hour, in-block stained with lead citrate, followed by dehydration and embedding in Spurr's [1969] Epon. Several 'thick' sections at $1.0 \mu \mathrm{m}$ were stained with toluidine blue and used for general orientation. Thin sections for electron microscopy were cut from separate tissue pieces in transverse and sagittal planes, collected on Formvar-coated grids and viewed on a Hitachi H 7000 and a JEOLJF microscope. One 22-mm-long larva was used in a later attempt 
in 1994. That specimen was also fixed in Trump's solution and sectioned into three pieces, but left in the fixative from November 11,1994 , until processing began on December 27. The same procedure as in 1991 was used except that uranyl acetate was employed instead of lead citrate for whole-block immersion staining, and all micrographs were obtained with the Hitachi $\mathrm{H}$ 7000. The 15-mm larvae of 1991 were at a stage when two to three rows of plates had developed, while the 22-mm specimen of 1994 showed five rows of developing electrocytes.

All original research reported herein was performed under guidelines established by the German, United States, and Brazilian authorities.

\section{Results}

\section{Development of Larvae in Their Nests}

Details of nest construction, brood care, and larval development have been reported previously [Assunção and Schwassmann, 1995]. To summarize the earliest growth, egg deposition lasted one day and was followed by an eight-day incubation period. Hatching was variable as to time and state of development. Most of the embryos emerged within a two-day period. While the earlier ones were completely white, the last ones to hatch had pigmented eyes. All had their heads lifted off the yolk sac when 7-10 mm long. For about six days after hatching, they did not show coordinated swimming movements and were heavier than water. Those that became dislodged from the foam nest immediately sank to the bottom, especially inside aquaria, where they soon died since their occasional tail beats did not move them back to the surface. This eleuthero-embryonic phase [Balon, 1975], or transition from embryo to larva, lasted from six to ten days when filling of mouth and gas bladder with air took place, and when oriented swimming and exogenous feeding were observed. These larvae were in transition from light- to dark-pink color and had air in the gas bladder and buccal cavity. From here on, pigmentation progressed rapidly and the larvae soon resembled little tadpoles, especially by their 'wriggling' swimming movements inside aquaria where their foam nests had rapidly disintegrated, something that was not observed in their natural nests where the hatchlings remained in a tight clump in the center of the foam nest. At about $30-\mathrm{mm}$ length, the tadpole-like swimming was gradually replaced by sideways flipping of the tail, combined with undulating waves of the anal fin. This last locomotor pattern became more pronounced when they reached $40 \mathrm{~mm}$ and when their aggressiveness became very noticeable; several cases of cannibalism were recorded in aquaria. The transition from the larval to the juvenile period occurred in the 40- to $50-\mathrm{mm}$ length range when the dorsal embryonic fin fold disappeared and lepidotrichial muscles of the anal fin became fully developed.

\section{Earliest Appearance and Maturation of Electrical Activity}

During field work in 1989, we obtained our first record of electrical activity from one specimen $15 \mathrm{~mm}$ in length, seven days after hatching, in the form of 20 - to $30-\mathrm{mV}$ amplitude and 4.0-ms-duration head-positive pulses, the down-going phase of which exhibited a conspicuous notch (fig. 1a, b). In the following years $(1990,1991)$, we obtained very similar records of single and multiple pulses of 6- to 30-mV amplitudes from two additional specimens. When repeating measurements from the same 20to $30-\mathrm{mV}$ pulse specimen of figure $1 \mathrm{a}, \mathrm{b}, 20 \mathrm{~h}$ later, we found its pulses now reaching $150 \mathrm{mV}$, while the duration had decreased to $1.5 \mathrm{~ms}$ (fig. 1c), and the negative phase now lacking the notch noted earlier (fig. 1a,b). Five larvae $16 \mathrm{~mm}$ in length showed amplitudes from 65 to $250 \mathrm{mV}$ and the discharges were mostly in the form of single or double pulses, while trains of up to 10 pulses were less frequent (fig. 1d) and required stronger prodding. Amplitudes of 1.6-5.0 V were noted in 20- to 22-mm-long specimens in which multiple pulses were also more easily elicited (fig. 1e). There was about $30 \%$ variability seen in pulse amplitudes recorded from the same individual in the same session. This was probably due to variation in electrode spacing with respect to the moving specimen. Also, when water was removed from the recording chamber, amplitudes increased by about $40 \%$. Pulse height variation was not caused by the animal discharging at different amplitudes because repeated pulses of one train were rather uniform and occasional changes of pulse voltages that occurred during an observed turn of $180^{\circ}$ were very gradual (fig. 1f). A summary of pulse voltages during the growth of young larvae is shown in figure 2, where high amplitudes (mostly in trains) and low voltages (mostly single pulses) are both entered and connected by a vertical line. Although some small differences in voltage levels are already present in the youngest, a dramatic change in the discharge pattern occurs at a length of about $45 \mathrm{~mm}$. Here, the difference between the two voltages becomes greatly accentuated, changing from an earlier approximately 2:1 to a nearly 5:1 ratio (right side of fig. 2a). Electrical activity now resembles the adult pattern, of which examples from a juvenile eel can be seen in figure $1 \mathrm{~g}$, h. To show further progression of discharge pattern development, the semilogarithmic plot in figure $2 \mathrm{~b}$ uses voltage measurements from laboratory-reared speci- 

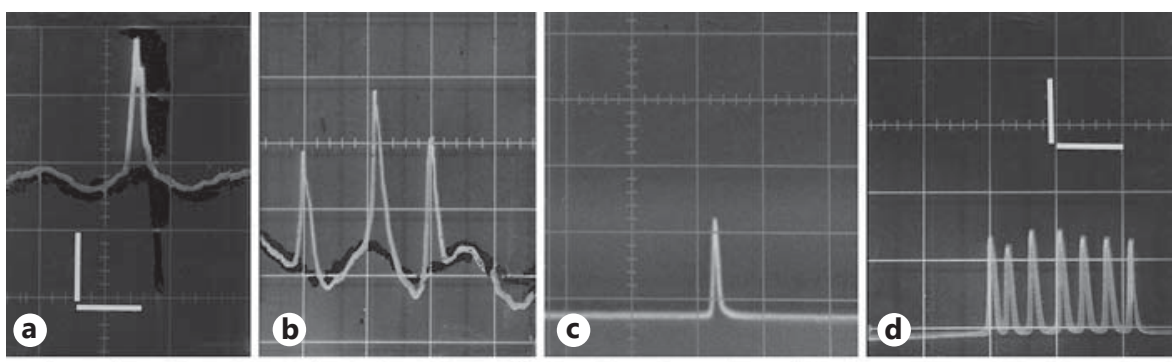

Fig. 1. Early appearance and maturation of electric discharges. Traces were photographed from a storage screen oscilloscope in the field. a, b Examples of earliest-recorded pulses from a 15-mm-long eel larva. Calibration $10.0 \mathrm{mV}$ and $10.0 \mathrm{~ms}$. c, d Electric pulses from the same larva one day later. Calibration $100 \mathrm{mV}$ and $10 \mathrm{~ms}$. e, f A spontaneous double pulse and a series of pulses with changing amplitudes during observed turning movement of a $22-\mathrm{mm}-$ long larva. Calibration $1.0 \mathrm{~V}$ and $10 \mathrm{~ms}$. $\mathbf{g}, \mathbf{h}$ Typical adult discharge recorded from one 105- and one 110-mm-long juvenile eel. A low amplitude orientation pulse precedes a train of pulses at shock amplitude. Calibration $10 \mathrm{~V}$ and $10 \mathrm{~ms}$ (note the 60 -cycle interference in $\mathbf{a}$ and $\mathbf{b}$ when no filter was used. All calibrations are from the settings of the built-in vertical and horizontal amplifiers).
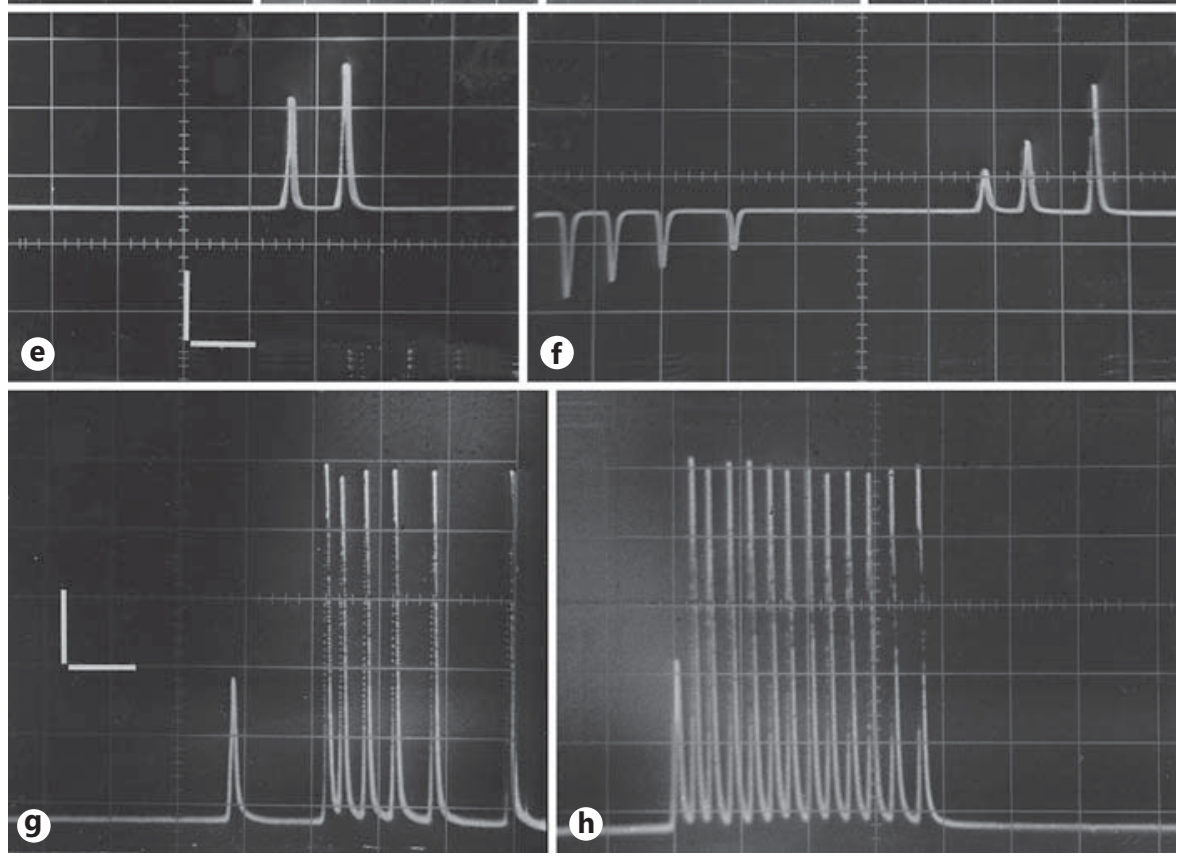

mens. From a length of around $110 \mathrm{~mm}$ onwards, the low-voltage orientation pulses stabilize around the 20volt level, as we find it in adult eels. The high-voltage 'shock' level, however, continues to increase with increasing size, reaching $225 \mathrm{~V}$ in a $385-\mathrm{mm}$ specimen (fig. $2 \mathrm{~b}$ ).

\section{Behavioral Correlates of Electrical Activity}

Audiomonitoring of larval pulsing activity inside aquaria gave some information about the utilization of electrosensory abilities. Field recordings from nests with early larvae yielded a constant high-volume hum from this mass of some hundred little eels, each of which probably only occasionally gave off a few pulses. No isolated pulses could be recorded in the field, the hum merely changed in amplitude when the electrodes moved around the nest and became inaudible at a distance of about $30 \mathrm{~cm}$. Recordings from a smaller number of individuals inside aquaria were easier to interpret. Early black 'wrigglers' 22-30 $\mathrm{mm}$ in length exhibited increased pulsing whenever a mechanical disturbance occurred or when food was introduced. Almost no pulsing was noticed when all individuals were hanging head up at the water surface, mostly along the side of their tank. Pulse rate increases came from those individuals that ventured away from the group, mostly to renew the air bubble in their mouth. During feeding, even when in a closed group, pulsing rate was high. In larvae of over $35 \mathrm{~mm}$, it appeared to be interrupted by frequent bursts of discharges, resembling 'shocks' of older eels. These bursts occurred regardless of whether the food was alive (mosquito larvae) or inert (fish roe). Larvae of this last size and older were also seen to 'attack' the active electrode of the recording instrument, giving off bursts of pulses. We did not monitor electrical activity at night but found evidence of aggressive behavior in the form of missing, or dead and mutilated, mostly smaller larvae. Two 35$\mathrm{mm}$ specimens were found one morning with their crania slit open; one had its brain missing. Schooling be- 


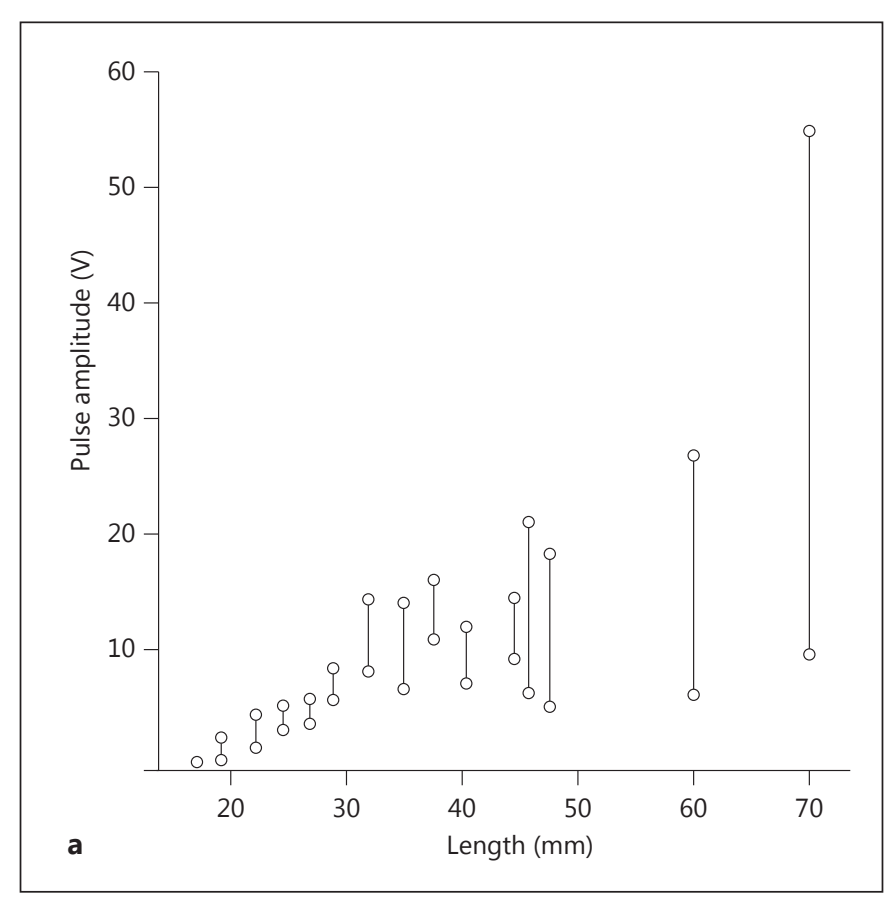

Fig. 2. Graphic presentation of recorded amplitudes from larval and juvenile electric eels. Plotted are the differences between high and low voltages, mostly recorded from single pulses and trains. The left graph (a) shows data from small fish, while the semiloga-

havior became less noticeable from $40 \mathrm{~mm}$ on. Although larger specimens, when kept together in an aquarium, would tend to remain aligned alongside each other, this appeared to be more incidental rather than an active schooling behavior. Two juveniles 100 and $115 \mathrm{~mm}$ in length that were kept together with some small guppies in a small aquarium showed dominant aggressive and submissive behavior, respectively. Already on the first day, the smaller eel remained hidden in Eichhornia roots, pulsing only when renewing air, while the larger one was almost constantly cruising through the tank, mostly near the bottom. The latter's orientation pulse frequency increased when it was making back-and-forth movements. During a one-hour observation in dim light, we recorded several very brief high-voltage bursts of 2-5 pulses and at least two longer lasting 'shocks' of 36 and 58 individual pulses in trains, emitted at a frequency of $290 \mathrm{~Hz}$, apparently while encountering or capturing prey. No actual attack of the larger eel on the smaller individual was observed. Adult eels, when kept together in large numbers in a tank, or when together in residual water holes during the dry season, will normally not aggress each other.

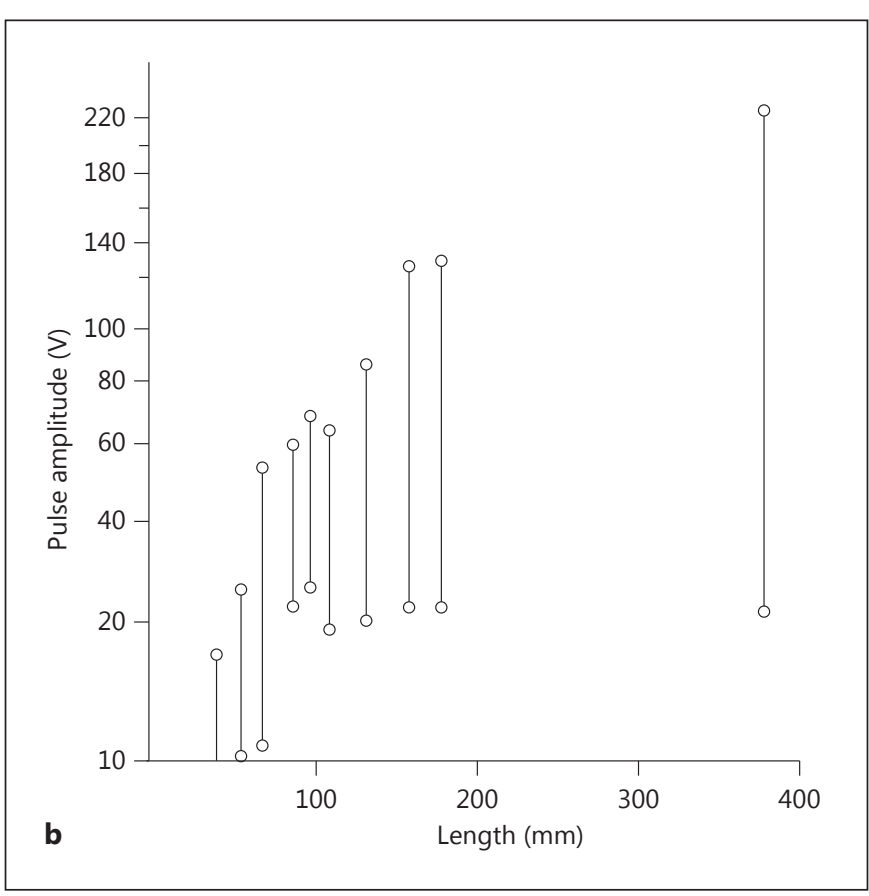

rithmic plot (b) shows larger juveniles. The difference in the two levels becomes very pronounced at a length of $45 \mathrm{~mm}$, while the low amplitude of orientation pulses stabilizes near $20 \mathrm{~V}$ at round $100 \mathrm{~mm}$ in length.

\section{Origin of Electromatrix and Early Electrocytes}

Hatchling of $10 \mathrm{~mm}$ (100 Somites). The transverse section in figure $3 \mathrm{a}$ reveals a bilateral small-celled region at the ventral tip of the myotome that we interpret as the presumptive origin of the future electromatrix. This particular area is visible in all sections through the tail of this embryo, varying in size and appearance in a metameric fashion, in correspondence with the myotome lying dorsad.

Larva of $15 \mathrm{~mm}$. The transverse view in figure $3 \mathrm{~b}$ depicts the germinative region of Keynes [1961], our 'matrix', which lies ventral to two already formed electrocytes, of which the dorsal one had formed first and is larger than the second one lying below. Dorsal to the electrocytes are the hypaxial trunk muscles located lateral to the two cardinal vessels and the ventral part of the notochord. They are clearly demarcated from the border of the first electrocyte.

Larva of $25 \mathrm{~mm}$. Eight columns are visible in this cross section (fig. 3c); they appear dorsoventrally compressed compared to the previous stage. Up to three successive plates appear in the same row, since the electrosepta, separating the plates of a column, are no longer oriented at a 
$90^{\circ}$ angle to the longitudinal axis. A lateralis imus muscle can be seen growing mediad from the lateral integument towards the lateral border of each matrix. Bundles of electromotor nerve fibers are visible, passing along the median septum that separates the two lateral halves of this future main organ. These axons originate from electromotor neurons in the mediodorsal aspect of the spinal cord (fig. 3d). A higher magnification of the germinative zone in figure $3 \mathrm{e}$ shows the lateralis imus muscle approaching the electromatrix from which two to three newly forming electrocytes seem to be splitting off. Obliquely running segmental external fin ray muscles are well developed and lie lateral to the not quite developed inner fin ray muscle and cartilaginous lepidotrichium. An obliquely cut section in figure $3 \mathrm{f}$ illustrates extra-electrocyte compartments and the electrocyte electroplasm. Numerous nuclei are concentrated near the posterior face, opposite from the papillary anterior face. A parasagittal section (fig. 3g) through the organ of one side shows seven rows of electrocytes. The electromatrix lies at the very bottom of the picture. The earliest row of electrocytes on top of the picture exhibits the metameric organization, in correspondence with the embryonic myomeres. However, two to three times as many units, as are present in the first row, are seen in the next columns. The noticeably wider spacing of plate compartments of the first developed column is retained in older specimens, which we could verify in several juvenile and adult eels. In one 860-mm-long specimen, a wider spacing of units was noticed in two to three dorsal rows, at a level of $260 \mathrm{~mm}$ from the snout, which is a level much farther anterior than what is normally considered the anterior beginning of Sachs' organ. Concerning electrocyte details, the larger

Fig. 3. Histological preparations to illustrate the early formation of electrocytes in electric eel embryos and larvae. a Transverse section through the tail of a $10-\mathrm{mm}$-long embryo at hatching. All myotomes in the anterior and middle part of the tail of the 100-somite embryo exhibit a small-celled ventral region that is interpreted as the presumptive electromatrix (em). b Transverse 1.0- $\mu$ m section from a 15-mm larva, showing electromatrix (em), and earliest (1) and second (2) electrocyte and hypaxial trunk muscle (m). c Transverse section of a 25 -mm larva with eight columns (e.g. 1, 2, 3) of electrocytes. The double arrow points to the medium septum and the single arrow to the lateralis imus muscle. d Transverse cut through the dorsal part of a 25-mm larva showing the spinal cord with large electromotor neurons. Dorsal root and ganglion (single arrows) and ventral root (double arrow) are indicated. e Transverse section through the germinative region of a $25-\mathrm{mm}$ larva shows the lateralis imus muscle (single arrow) and the external fin

Ontogeny of Electric Organs in the Electric Eel anterior extrasyncytial compartments are easily distinguished from the narrower posterior chambers in which motor nerve axons (not visible in the figure) make synaptic contacts at the posterior face of the electrocyte. The anterior face exhibits numerous large papillae.

\section{Successive Electrocyte Formation Stages Visible within} the Same Specimen

Looking through a set of serial sections from one larva, it becomes apparent that the more caudad one moves, the earlier the developmental state shown by the section. One can thus review conditions as they had existed earlier in the anterior part of the animal. Or, to state it differently, successive stages of electric organ development can be observed in the very same animal. This is shown in the five sections from a $25-\mathrm{mm}$ eel larva in figures $3 \mathrm{~h}-1$. Five plates have formed in the section shown in figure $3 \mathrm{~h}$, while epi- and hypaxial trunk muscles are in an early formative state. Progressing caudad, three and four electrocytes and a long axonal bundle can be discerned in figure $3 i$, while only one or two early electrocytes with an innervating nerve bundle are seen in figure $3 \mathrm{j}$. Only one developing electrocyte dorsal to one of the bilateral matrix zones and little myotube formation in the dorsal trunk muscle area are noticed at the more posterior level in figure $3 \mathrm{k}$ and would correspond to the early ontogenetic stage seen in figure 3a. Little matrix development from a suspected precursor mesenchyme and hardly any trunk muscle myotube formation are seen in the most caudal section (fig. 3l). Two striking differences are noted when comparing the tail end sections with more anterior ones of younger specimens, where the same number of electrocytes is present. First, trunk muscle development in the

ray muscle (arrowhead). f Transverse cut through an electrocyte column at higher magnification. Single arrow points to the longitudinally running intercolumnar septum, and anterior (af) and posterior faces (pf) and the electrocyte plasm (ep) are indicated. g Parasagittal section through the electric organ of a 30-mm larva. The uppermost (earliest) row of plates was formed in precisely metameric order, whereas the following columns, visible towards the bottom of the figure, exhibit denser and denser spacing. The arrow points anteriorly. The thick arrowhead shows the longitudinal septum between columns 1 and 2, while the thin arrowhead indicates the posterior face of an electrocyte of the first column. h-I Selected transverse sections through the tail of a 25-mm larva demonstrate earlier developmental stages as one progresses posteriorly, as indicated by the smaller number of already formed electroplates. $\mathrm{n}=$ Electric nerve; em = electromatrix. Bars $=25 \mu \mathrm{m}$ $(\mathbf{a}, \mathbf{b}, \mathbf{f}) ; 50 \mu \mathrm{m}(\mathbf{d}, \mathbf{e}, \mathbf{g}, \mathbf{i}-\mathbf{I})$, and $100 \mu \mathrm{m}(\mathbf{c}, \mathbf{h})$.

(For figure see next page.) 

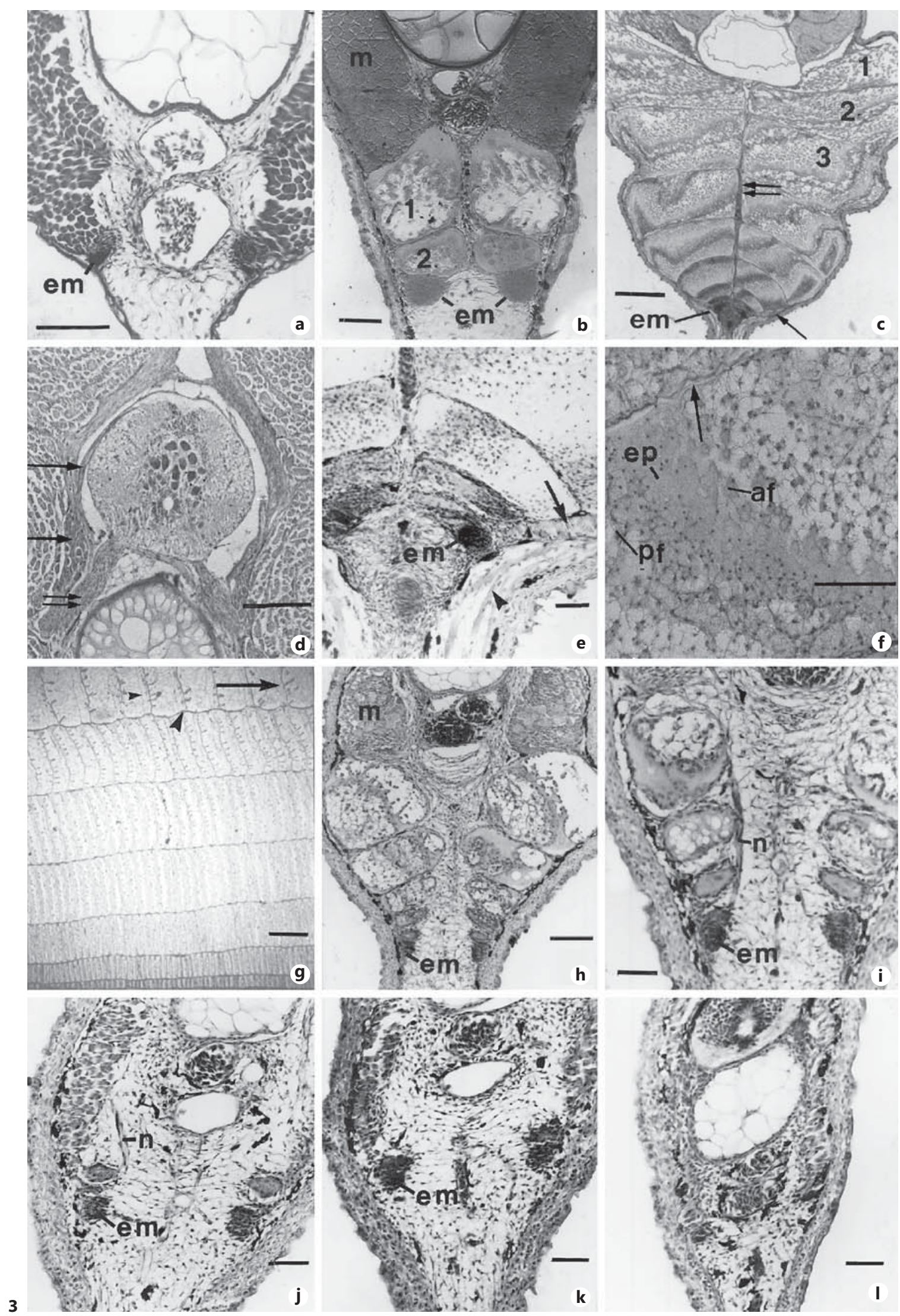
Fig. 4. a Lateral part of the germinative zone from a 22-mm larva with pre-electroblasts. Fibroblasts (fb) mark the outer border. Bar $=1.0 \mu \mathrm{m}, \times 10,400$. b Very early stage of electrocyte development from the 22-mm larva. One pre-electroblast (pb) and several electroblast muclei are visible, the latter producing abundant electroplasm (epl). The cell membrane of the fibroblast (fb) marks the edge of the developing electrolemma (arrow) where the first caveolae are forming: Golgi membranes (arrowheads). Bar $=1.0 \mu \mathrm{m}, \times 7,800$.
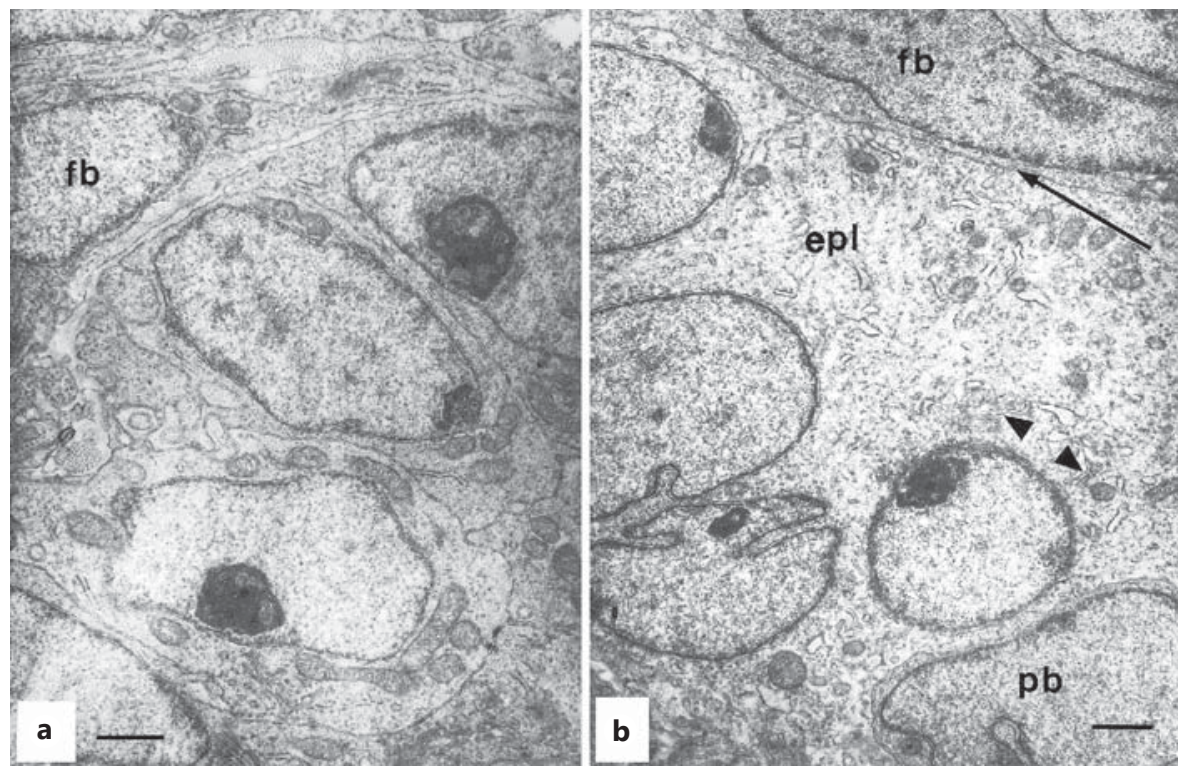

tail appears to lag somewhat the electric organ development and, secondly, the bilateral columns of electrocytes in the tail end are separated widely by mesenchyme, while they are seen to abut each other in the anterior part of the tail (compare fig. $3 \mathrm{c}$ with $\mathrm{h}, \mathrm{i}$ ). The correspondence in position of the electromatrix in the embryo at hatching (fig. 3a) and in the tail end of the 25 -mm larva (fig. $3 \mathrm{k}$ ) is striking.

\section{Fine Structure of Developing Electrocytes in Early Larvae}

Classification of Progenitor Cells. Electron micrographs of the matrix region show two types of electrocyte precursor cells. We consider as 'pre-electroblasts' those cells that are concentrated in the ventrolateral part of the matrix and are surrounded by a double membrane, enclosing a rather small volume of cytoplasm. Occasional spot desmosomes, few mitochondria and Golgi membranes but no other organelles are seen in these pre-electroblasts (fig. 4a). In a newly forming electric plate, splitting off from the matrix in a dorsomedial direction, most cells have lost their membranes and have become mere nuclei. We like to classify these very active nuclei as 'electroblasts'. Their main activity seems to be the production of large amounts of 'electroplasm' with an increase in mitochondria and Golgi apparatus (fig. 4b). There is also an increase in spacing between the many nuclei which now become aligned along the periphery of the expanding syncytium (fig. 5a). While individual cell membranes disappear rapidly during the pre-electroblast to electroblast transition, a new syncytial 'electrolemma' forms at the periphery in contact with the connective tissue septa. We found occasionally what appeared to be active pairs of cells with both partners still adjacent, both with a membrane (fig. 5b), or one with and one without (fig. 5d). The location of these seemingly dividing pre-electroblasts was generally toward the base of the rapidly growing electric plate. After the earliest phases of electrocyte formation, when extrasyncytial compartments have formed and the former electroblasts are lined up along the periphery of rostral and caudal faces, we may call them 'electrocyte' nuclei. Another type of cell seen in almost all of these budding electrocytes, at the time of early cytokinesis and before the opening of extrasyncytial compartments, is conspicuous by its sparse and electron-dense cytoplasm (fig. 5a). We like to designate these cells as 'satellite' cells since they are also seen in micrographs of the next developmental stage where they lie outside of the electrocyte compartment (fig. 6b).

Cytokinetic Phase. Very early, as soon as some central electroplasmic space has formed in-between the nuclei, occasional myofilaments appear near several of the electroblast nuclei (fig. $5 \mathrm{c}, \mathrm{d}$ ). They are the size of actin filaments, $800-1,000 \mathrm{~nm}$ long and about $6 \mathrm{~nm}$ thick. About $10-20$ of these filaments are attached to both sides of a dense structure that resembles a Z-fragment (fig. 5c, 6c). We like to designate as 'karyokinetic phase' this occurrence of early and relatively sparse investment with myofilaments near electroblast nuclei, as it is seen in figure $5 c$. 
Fig. 5. a Parasagittal section through an early row of forming electrocytes from the 22-mm specimen. Electrocytes (ec) alternate with electosepta (es) made up of fibroblasts $(\mathrm{fb})$. The previously formed row of electrocytes (upper left corner) already shows typical electrolemma (el). Satellite cells (arrows) lie outside of the electrolemma but inside the electrocyte boundary. Longitudinal septa (ls) lie between columns, medioventral is mesenchyme (mes). Bar $=5.0 \mu \mathrm{m}, \times 2,100$. $\mathbf{b}$ Enlarged view of a nearby early electrocyte shows pre-electroblasts $(\mathrm{pb})$ after mitosis. Arrows point to the cell membranes. Bar $=1.0 \mu \mathrm{m}, \times 7,500$. c, d Pre-electroblasts ( $\mathrm{pb}$ ) and electroblasts (eb) during the early cytokinetic stage. Some actin filaments (arrows) have already formed. Bars $=1.0 \mu \mathrm{m}, \times 7,800$.
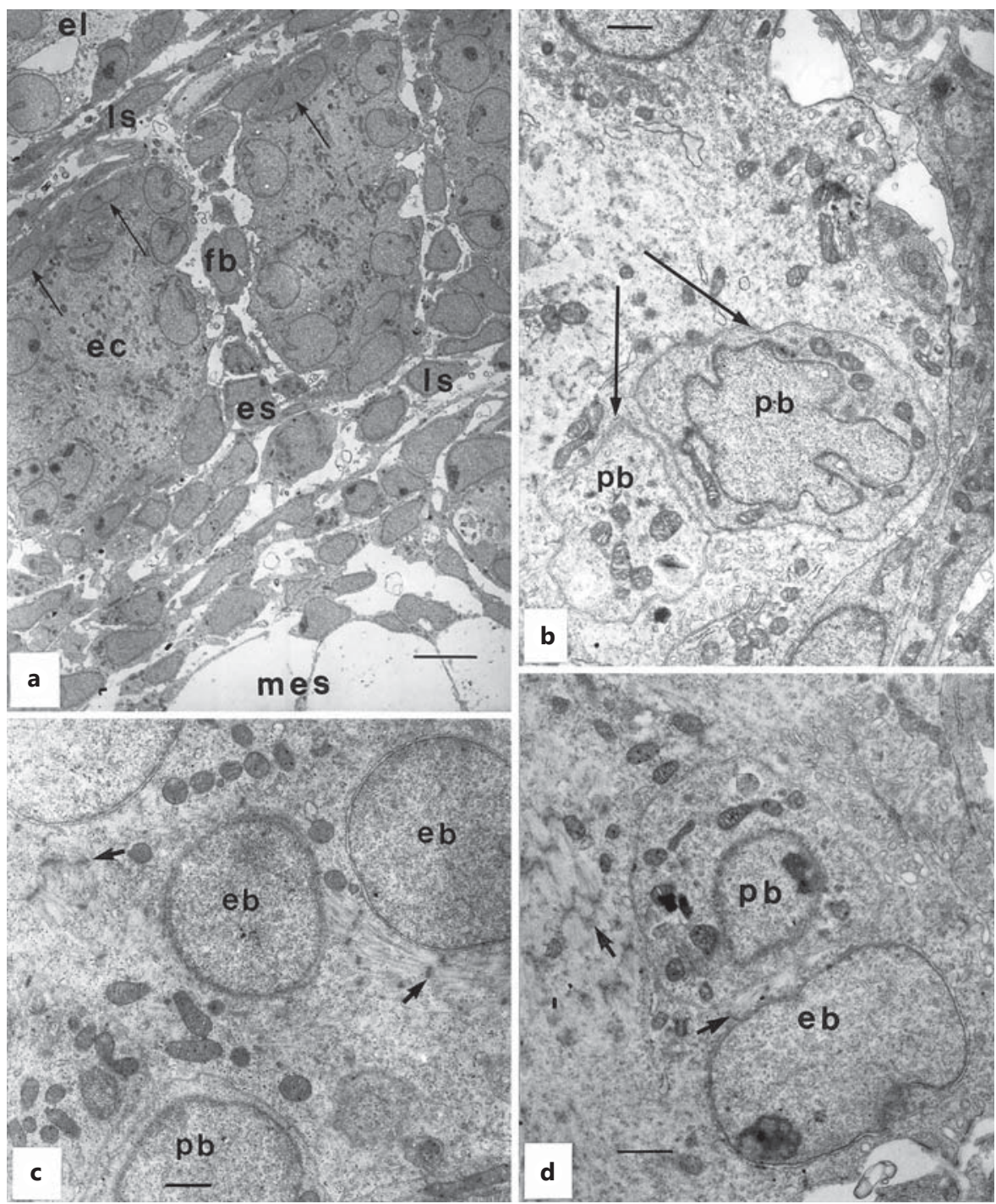

While we found these presumed actin filaments only occasionally in the smaller specimens of our 1991 series, we encountered a more extensive network of such filament assemblies in the central electrocyte area of the slightly larger larva of 1994 (fig. 6a, b). This myofilamental net was oriented in a specific plane in a very thin layer, so that it showed up in only a few successive transverse sections. Possibly as a result of some contractive forces, internal spaces are created (fig. 6a, b) with resulting syncytial membrane specializations in the form of characteristic 'caveolae' [Yamada, 1955; Luft, 1958], which are perforating the eventual electrolemma (fig. $7 \mathrm{~b}, \mathrm{c}$ ). Another possible consequence seems to be the opening up of rostral and caudal compartments, bounded externally by thin connective tissue sheets, the electrosepta, and harboring centrally the now thinning electrocyte. In the electrocyte row above the one that develops the inner space, nothing much of the earlier network of actin filaments remains but a scattering of loose fibers, visible only at high magnification (fig. 6d). A few Z-line fragments are barely discernible.

Electrolemma Specialization. Electrocyte nuclei are more numerous at the posterior innervated faces of the newly formed electrocytes (fig. 7a) than at the anterior faces (fig. 7b). Long and relatively straight caveolae are infoldings of the electrolemma, about 3.0-4.5 $\mu \mathrm{m}$ long. Occasional branching of caveolae is seen at a depth of 1.5 $\mu \mathrm{m}$. The diameter of these tube-like structures ranges from 65 to $155 \mathrm{~nm}$, with wider diameters occurring at the branching sites (fig. 7b). Caveolae of the posterior face are 
Fig. 6. a, b Transverse sections showing the cytokinetic stage of electrocyte development from the row dorsal to the one pictured (a). Abundant actin filaments (af) are visible. An early cavity begins to form on the right (arrow) which is greatly enlarged in the plate on the left side showing fully developed electrolemma (el). The actin filaments are beginning to disintegrate on the left; satellite cells (sat) lie outside the electroplasm (b). Bars $=2.0 \mu \mathrm{m}, \times 5,000$. c Higher magnification of the array of actin filaments (af) attached to Z-bandlike structures $(\mathrm{z})$. Bar $=0.5 \mu \mathrm{m}, \times 25,000$. d Only traces of disorganized filaments (double arrow) remain inside and below the caveolar layer. Bar $=1.0 \mu \mathrm{m}, \times 15,000$.

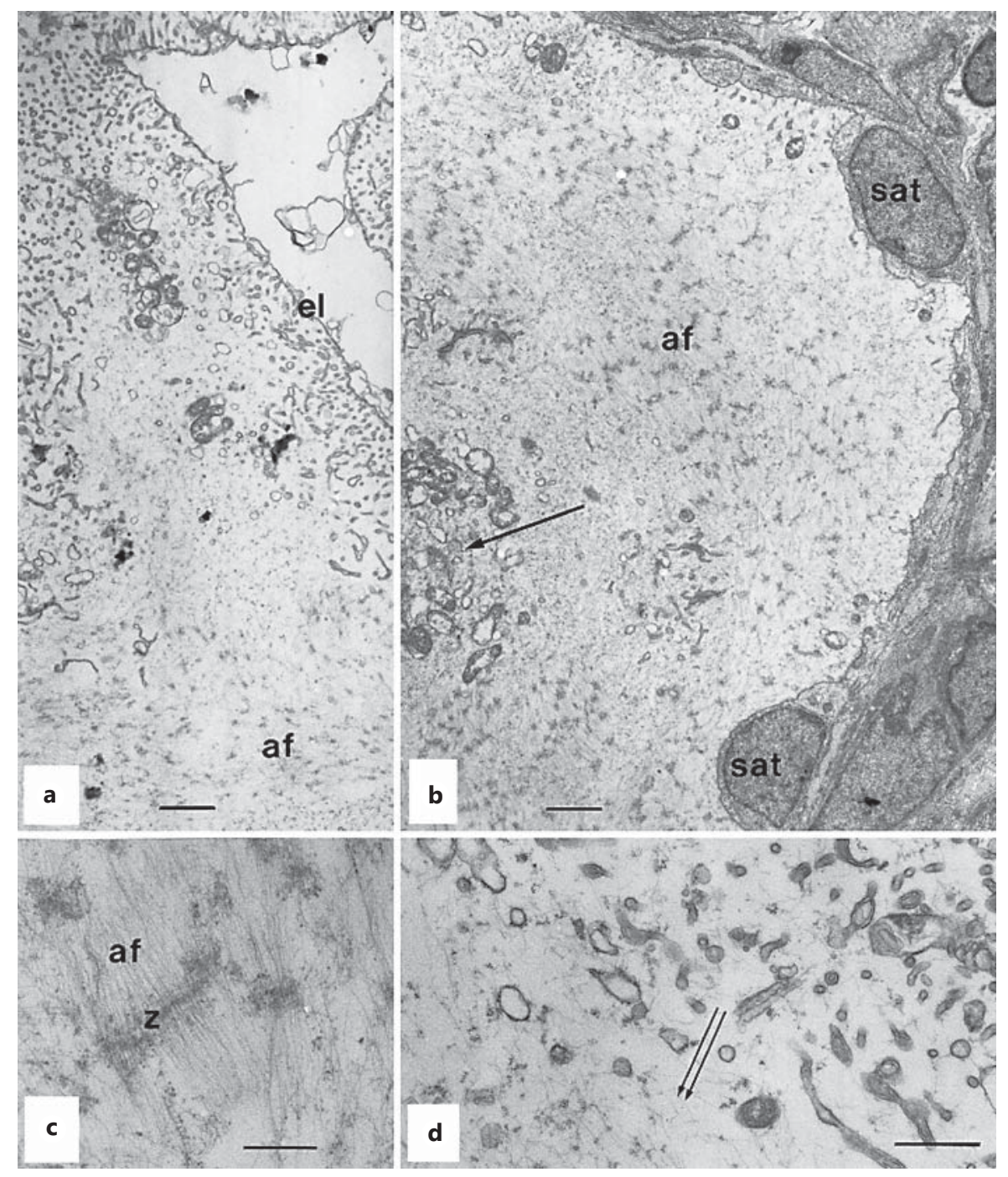

shorter and more convoluted, of the same diameter but only an average of $500 \mathrm{~nm}$ long. A fibrillar coat covers all electrolemma and continues throughout the caveolae (fig. 7b, c). This filamentous border consists of fine hairs 44-80 $\mathrm{nm}$ in length and appears to be somehow involved with the apparent double layer appearance of many vesicles and large-bore caveolae. In addition to these doublelayered larger vesicles, we find small and large singlemembrane vesicles at, or deeper than, the caveolar layer (fig. 7b).

Early Appearance of and Eventual Nervous Innervation. While inspecting details of very early plate formation stages, especially during first karyokinesis and electroplasm expansion, we encountered occasional accumulations of small profiles that appeared to be axonal branches. Most were filled with synaptic vesicles and several synapses were detected (fig. $7 \mathrm{~d}, 8 \mathrm{c}$ ). When the posterior syncytial membrane is fully formed, axon terminals and synapses are numerous (fig. 7a). Axon terminals on the posterior face of the electrocytes were usually $0.5-1.5$ $\mu \mathrm{m}$ (fig. $8 \mathrm{a}$ ), with a few multisynaptic terminals reaching $6.4 \mu \mathrm{m}$ in the long axis (fig. 8b). Synaptic clefts were $55-90$ $\mathrm{nm}$ wide and showed a dense centerline, while synaptic vesicles measured 55-90 $\mathrm{nm}$ in diameter. Mitochondria were most frequent at a depth of 2.6-8.0 $\mu \mathrm{m}$; their diameters were $0.4-1.0 \mu \mathrm{m}$ in the electroplasm and $0.2-0.6 \mu \mathrm{m}$ in axons, with one noted exception of a $0.97-\mu \mathrm{m}$ axonal mitochondrion (fig. 8c). This same electron micrograph from the $15-\mathrm{mm}$ specimen also shows an unusually high number of axonal profiles. 
Fig. 7. a Cross section through posterior face papillae (pp) with many nuclei (n), axonal branches (arrows) and Schwann cell nucleus $(\mathrm{sc})$. Bar $=5.0 \mu \mathrm{m}, \times 3,700$. b Section through electrolemma (el) of the anterior face. Caveolae (arrow) are longer than on the posterior face and show branching. Some large single-walled vesicles (arrowhead) are present. Bar $=1.0 \mu \mathrm{m}, \times 15,000$. c Enlarged view of the anterior face electrolemma, showing the hairy coat (arrowhead) which extends into the caveolae (arrow). Bar $=0.5 \mu \mathrm{m}, \times 30,000$. $\mathbf{d}$ Early sign of innervation during electrocyte formation in the $15-\mathrm{mm}$ larva. The first caveolar vescicles (arrowhead) begin to break through the posterior face electrolemma (arrow). Many axonal branches (double arrows) make contact with the electrolemma. Bar $=1.0 \mu \mathrm{m}, \times 8,600$.
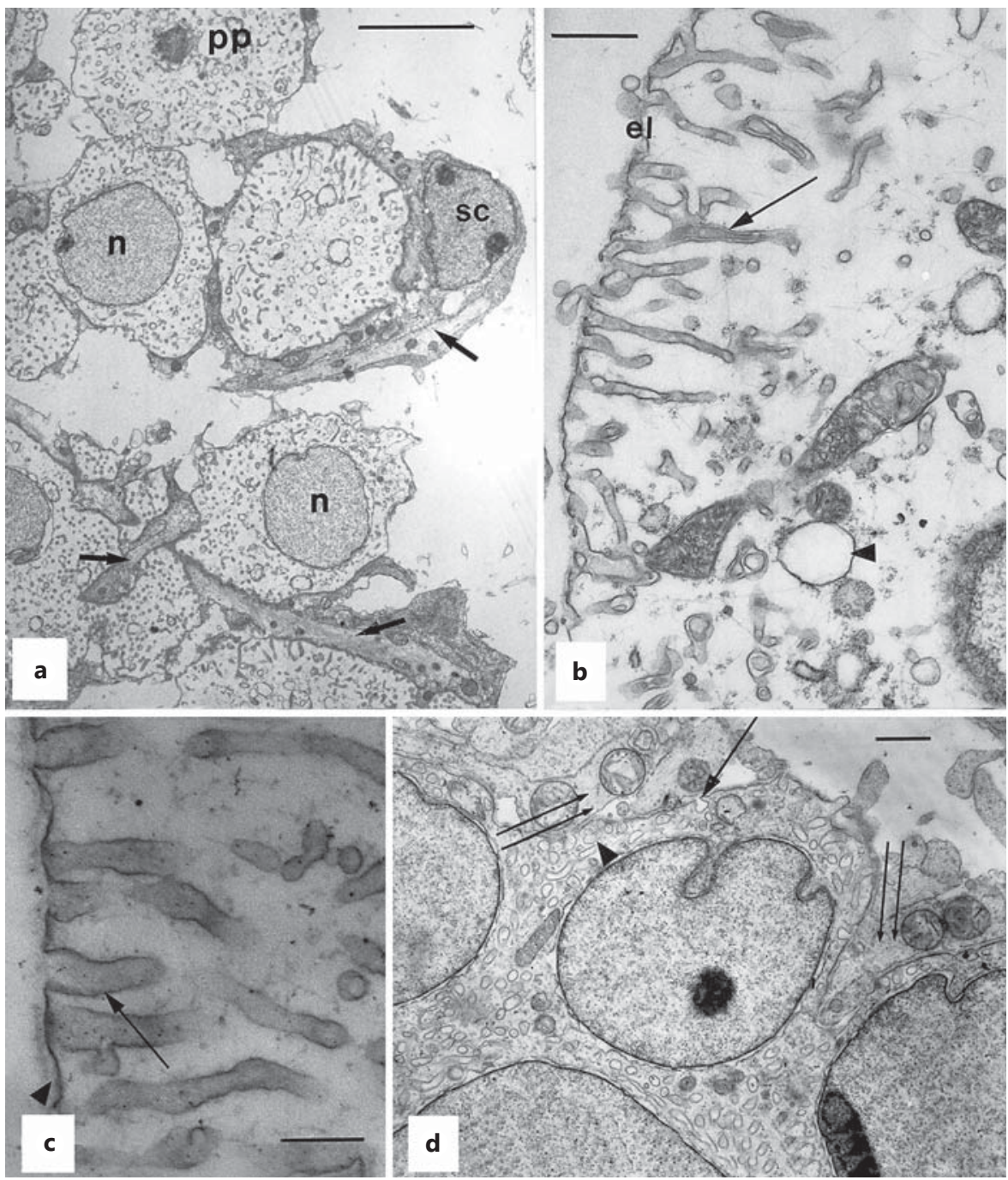

Myofiber Genesis Observed Adjacent to the Electromatrix. Beneath the pigmented epithelium, lateral to the electromatrix, we encountered some developing myofibers. These isolated developing myotubes showed up as single red-staining spots in paraffin-embedded material of small larvae. They could be identified in the larger specimen as an early stage of the lateralis imus muscle. The fundamental difference between the formation of an organized myofibrillar system and the actin filament system during electroplate cytokinesis (fig. 5c-6c) shows up clearly when inspecting an early myotube, found lateral to the matrix zone of the 15 -mm larva (fig. $8 \mathrm{~d}$ ), as well as more advanced myotube stages from the older larva (fig. 8e, f).

\section{Discussion}

We demonstrate that formation of the first columns of electrocytes in the pulse-type gymnotiform E. electricus begins during the transition from the embryonic to the larval phase, and that early electric activity can be elicited at this time. Our material shows how electrocytes originate directly from a matrix, designated by Keynes [1961] as germinative region, ventral to developing trunk muscle; this early matrix splits off from the ventral segmental myotome in the 100-somite embryo at hatching. We see no evidence which would support a gradual, or sudden, transformation from already existing skeletal muscle into electrocyte tissue. Though Keynes [1961] was the one to recognize the role of the matrix zone in electric organ for- 


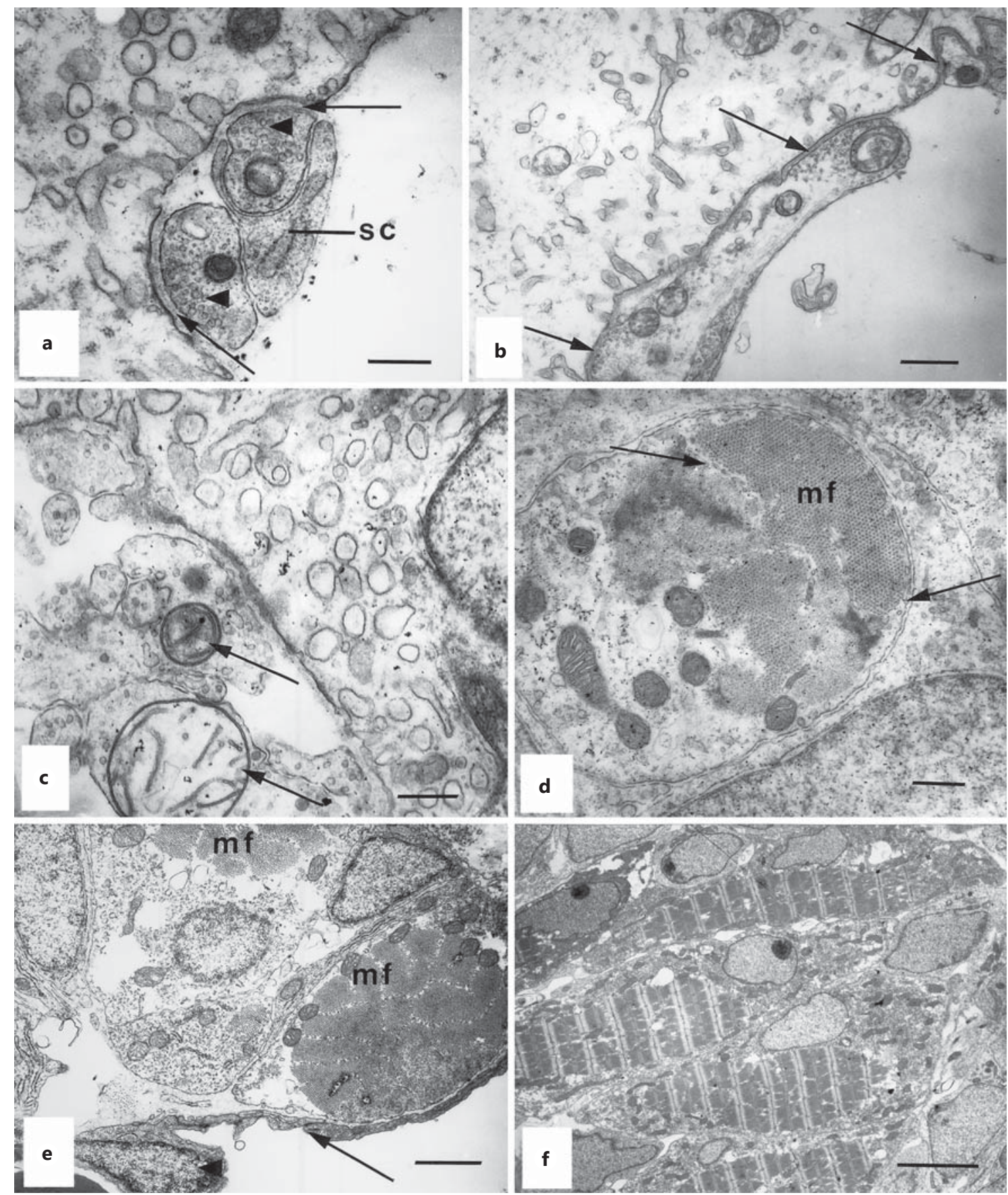

Fig. 8. a Synaptic terminals at posterior face electrolemma. Synaptic clefts (arrows), vesicles (arrowheads), and a Schwann cell (sc) are visible. Bar $=0.5 \mu \mathrm{m}, \times 22,000$. b An elongated axonal terminal: arrows point to synaptic clefts. Bar $=1.0 \mu \mathrm{m}, \times 11,000$. c A multitude of axonal terminals at the posterior electrolemma of the 15$\mathrm{mm}$ larva. Note the size difference in axonal mitochondria (arrows). Bar $=0.5 \mu \mathrm{m}, \times 22,000$. d Cross section from the $15-\mathrm{mm}$ larva showing early myotube with myofibrils ( $\mathrm{mf}$ ) forming; sarco- plasmic reticulum (arrows) is also visible. Bar $=0.5 \mu \mathrm{m}, \times 16,500$. e More advanced myotubes of the developing lateralis imus muscle from the 22-mm specimen. Myofibrillar systems ( $\mathrm{mf}$ ), endothelial lining (arrow), and endothelial cell nucleus (arrowhead) of an adjacent blood vessel. Bar $=2.0 \mu \mathrm{m}, \times 5,500$. $\mathbf{f}$ Longitudinal section through myotubes of the developing lateralis imus muscle from the $22-\mathrm{mm}$ specimen. Bar $=5.0 \mu \mathrm{m}, \times 2,750$. 
mation, this structure had been noted previously by Hunter [1775]. Fritsch [1881] also described it as a peculiar fibrous tissue occurring between inner and outer fin ray muscle, labelling it ' $y$ ' in his figures 18,20 , and 21, but placing it incorrectly in his figure 19. Szabo [1966] and Esquibel et al. [1971], both supported Keynes thesis as to the germinative role of the matrix zone; however, both claimed striated muscle involvement in electrocyte formation, based on their finding of extensive areas with myofibrillar components. Our own results confirm the findings of Esquibel et al. [1971], showing almost identical Z-line fragments with adhering actin-like filaments.

In our larval material, we could not find any conspicuous connective tissue separation between main and Sachs' organ, as was demonstrated by Luft [1957] in his adult material. This then raises the question of what organ part could be causing the constancy of low-voltage orientation pulses seen in our specimens of more than 45 $\mathrm{mm}$. Also, the persistence in older eels of wider interplate spacing in the first columns of electrocytes at a level far forward of what is normally taken as the anterior beginning of Sachs' organ could have implications for our understanding of the formation of the last-mentioned organ, and its sometimes questioned status as a separate entity [du Bois-Reymond in Sachs, 1881; Ballowitz, 1897]. Based on the information obtained in our present study, we feel encouraged to speculate that the widely spaced dorsal-most rows of oldest electrocytes and their progressive caudad extension could be the source of lowvoltage orientation pulses. Such reasoning could also explain the persistence of low-voltage pulses of 20-40 V after complete removal of Sachs and Hunter organs [Hagiwara et al., 1965]. Another apparent difficulty of interpretation lies in the very low amplitude of early pulses recorded from 15-mm larvae, even though histology and visual inspection of whole specimens detects about 20 electrocytes in the first and more in subsequent rows. Considering that transmembrane potential changes per unit must be $>100 \mathrm{mV}$ [Keynes and Martins-Ferreira, 1953], one would expect 100 times larger values. The low level of recorded voltages may be due to several factors, like current leakage and attenuation by our disproportionally large recording electrodes, poor synchronization of discharge, or activation of only a limited number of units. We recall that similarly low amplitudes of larval organ pulses were reported for the mormyrid Pollimyrus isidori by Denizot et al. [1978]. The adult pattern of discharge is first seen in larvae of $45 \mathrm{~mm}$ and is fully developed in specimens $100-115 \mathrm{~mm}$ in length, from which we recorded not only trains of high frequen- cies of up to $300 \mathrm{~Hz}$ but also brief double to quintuple high-voltage pulses, similar to the 'feeding and hunting responses' reported by Bauer [1979].

The electrogenic units, the electrocytes, are formed by electroblasts which develop directly from specific progenitor cells, pre-electroblasts. Similarities exist in earlystage myofiber and electrocyte formation. Myoblasts seem to partially fuse their cell membranes with those of other myoblasts to form myotubes, inside which the production of myofibrillar elements begins. Electroblasts, on the other hand, dissolve their membranes completely before producing electroplasm. The syncytial electrolemma seems to develop de novo and not simply by fusion of pre-electroblast membranes.

The exact pathways and possible inductive processes by which pluripotential stem cells in the early embryo's somatic mesoderm differentiate into progenitor cells for muscle and electrocyte elements are not known.

Recent experimental work on the regenerating blastema after tail amputation in Sternopygus macrurus, utilizing immunochemical antibody analysis, as reported by Zakon and Unguez [1999], Unguez and Zakon [2002], for example, seems to indicate great flexibility in myocyte or electrocyte determination in that particular species. The last mentioned authors also report a determining role of nervous innervation for electrocyte formation. The apparent difference in observed ontogenetic pathways between our electric eel study and the Sternopygus results could perhaps mean a more primitive, or earlier, evolutionary pathway represented in the latter species, as indicated also by our findings of electrocyte origin in epi- and hypaxial muscle in that species [Kirschbaum and Schwassmann, 2008). It could also indicate that regeneration after tail amputation occurs in a different fashion than during normal ontogenetic development.

With respect to a possible functional significance of the actin filaments observed in early electrocytes, they may be involved in the movement of electroblasts to the future rostral and caudal faces, as their sudden appearance next to the dissolving nuclear envelope of newly generated electroblasts would indicate (fig. 5c, d). Additional involvement might be indicated in forming cytoplasmic constrictions inside the electroplasm (fig. 6a, b), which eventually cause the formation of thin electrocytes with rostral and caudal separation of the electrolemma from the connective tissue of vertical electrosepta. In such assumed cytokinetic activity, only slow movements would be needed and these may be possible, in the absence of cross-bridge-equipped myosin filaments, by interaction of the twisted strands of helically wound actin polymers. 
Most other features observed by us are in line with previous results of studies on fully developed electrocytes, except that we failed to see synapses located exclusively along the papillae of the posterior face [Machado et al., 1980]. At least in the youngest larvae, we see them more frequently on the main body of the syncytium, while about equal occurrences of synaptic endings on the main body and on the posterior papillae were found in the older specimen. We have no evidence concerning the formative process that results in the sudden appearance of the many caveolae. It could be similar to the fusion of aligned rows of vesicles with eventual breaking of the electrolemma, as observed in regenerating electrocytes of E. virescens by Baillet-Derbin [1978].

The observed doubling of membranes of caveolar invaginations and larger, probably connected vesicles may be an artifact. Similar caveolar membrane duplications can be seen, for example, in figure $5 \mathrm{~d}$ of the study on $S$. macrurus electric organ morphology by Mills et al. [1992]. Such possible artifacts were discussed by Maunsbach [1966] and blamed on different fixation methods.

Recently, we have been able to compare the ontogeny of electrocytes in seven species, belonging to five families of Gymnotiformes [Kirschbaum and Schwassmann, 2008]. We could distinguish two separate evolutionary lines of myogenic development, a type A where electroblasts form inside epi- and hypaxial trunk muscle, contrasted to a type B which appears to be a more derived condition with electroblasts separating earlier from the ventral tip of segmental mesoderm, as exemplified in our study on Electrophorus here. The separation of the two types is not rigorous as we see some aberrations. Two species of Gymnotus seem to represent a more primitive form of type B with a few single electrocytes located in hypaxial muscle. The most advanced or derived condition seems to exist in Electrophorus where the earliest electrocytes form the persisting main electric organ. At a length of around $12 \mathrm{~cm}$. Hunter's organ is formed from the same original matrix zone which formed the main organ. E. virescens exhibits type A formation in its larval electric organ, while the adult organ forms in the location characteristic for type B. Most gymnotiform species have a larval electric organ that is replaced at the end of the larval period by an adult organ. Exceptions are Brachyhypopomus pinnicaudatus, where the larval and adult organ seem to be the same [Franchina, 1997], and also S. macrurus, where the adult organ appears as a caudal extension of the former larval organ. Apteronotus leptorhynchus has a type A larval organ that is replaced by an adult neurogenic electric organ.

Ontogeny of Electric Organs in the Electric Eel
The principal feature leading to the development of electric organs seems to have been the synchronization and summation of membrane action potentials of many units of original muscle or nerve tissue. This allowed the production of electric signals and the detection of impedance changes due to nearby objects in the surrounding water by means of lateral-line-derived tuberous and ampullary electroreceptors. By multiplying the number of excitable units, the powerful electric organ of the electric eel evolved. Neurogenic electric organs are rarer, but are present not only in the Apteronotidae but also suspected to form accessory electric organs in several species. These are the submental organs in the genus Gymnorhamphichthys [Schwassmann, 1989], the postpectoral organs in the two species of Steatogenys [Schwassmann, 1984] and in Hypopygus lepturus [Nijssen and Isbrücker, 1972].

\section{Acknowledgments}

We are grateful to the Vieira family of Cachoeira do Ararí for the help in procuring material, and to Raimundo Aragão Serrão, Antonio Firmino Tota, and A.C.S. Martins, all of the Goeldi Museum, for their help in the laboratory. Thanks are due to Louis Guilette in whose laboratory at the University of Florida most of the histological work was done. The electron-microscopic preparations were executed at the Electron Microscopy Core of the Center for Biotechnology Research of the University of Florida with special thanks to Karen Vaughn of this facility. Preparation of figures and processing of additional material was performed at the Leibniz Institute of Freshwater Ecology and Inland Fisheries with the help of Liane Wieczorek. We thank Yvonne Kirschbaum for her help with the technical preparation of the paper. The senior author acknowledges a fellowship and a grant from the Brazilian Conselho Nacional de Pesquisas.

References

Assunção MIS, Schwassmann HO (1995): Reproduction and larval development of Electrophorus electricus on Marajó Island, Pará, Brazil. Ichthyol Explor Freshwaters 6:175-184.

Baillet-Derbin C (1978): Cytodifferentiation of the regenerating electrocyte in an electric fish. Biol Cell 33:15-22.

Ballowitz E (1897): Zur Anatomie des Zitteraals (Gymnotus electricus L.) mit besonderer Berücksichtigung seiner elektrischen Organe. Arch Mikr Anat 50:686-750.

Balon EK (1975): Terminology of intervals in fish development. J Fish Res Board Canada 32: 1663-1670.

Bass AH (1987): Electric organs revisited. Evolution of a vertebrate communication and orientation organ; in Bullock TH, Heiligenberg W (eds): Electroreception. New York, Wiley, pp 13-70. 
Bauer R (1979): Electric organ discharge (EOD) and prey capture behavior in the electric eel, Electrophorus electricus. Behav Ecol Sociobiol 4:311-319.

Denizot JP, Kirschbaum F, Westby GWM, Tsuji $S$ (1978): The larval electric organ of the weakly electric fish Pollimyrus (Marcusenius) isidori (Mormyridae, Teleostei). J Neurocytol 7: 165-181.

de Oliveira-Castro G (1955): Differentiated nervous fibres that constitute the electric organ of Sternarchus albifrons, Linn. Anais Acad Bras Ciências 27:557-560.

-Esquibel MA, Alonso I, Meyer H, de OliveiraCastro G, Chagas C (1971): Quelques aspects de l'histogenèse de l'ontogenèse des organs électriques chez Electrophorus electricus L. CR Acad Sci Hebd Seances Acad Sci D 273:196199.

-Franchina CR (1997): Ontogeny of the electric organ discharge and the electric organ in the weakly electric pulse fish Brachyhypopomus pinnicaudatus (Hypopomidae, Gymnotiformes). J Comp Physiol A 181:111-119.

Fritsch G (1881): Vergleichend-anatomische Betrachtung der elektrischen Organe von Gymnotus electricus; in Sachs C (1881): Untersuchungen am Zitteraal Gymnotus electricus. Leipzig, Veit, pp VI-VIII, 347-400.

-Hagiwara S, Szabo T, Enger PS (1965): Physiological properties of electroreceptors in the electric eel, Electrophorus electricus. J Neurophysiol 28:775-783.

Hunter J (1775): An account of the Gymnotus electricus. Phil Trans Roy Soc (London) 65: 395-407.

Keynes RD (1961): The development of the electric organ in Electrophorus electricus L; in Chagas C, Paes de Carvalho A (eds): Bioelectrogenesis. Amsterdam, Elsevier, pp 14-19.

Keynes RD, Martins-Ferreira H (1953): Membrane potentials in the electroplates of the electric eel. J Physiol 119:14-18.
Kirschbaum F (1975): Environmental factors control the periodical reproduction of tropical electric fish. Experientia 31:1159-1160.

-Kirschbaum F (1977): Electric organ ontology: distinct larval organ precedes the adult organ in weakly electric fish. Naturwissenschaften 64:387-388.

Kirschbaum F (1979): Reproduction of the weakly electric fish Eigenmannia virescens (Rhamphichthyidae, Teleostei) in captivity. I. Control of gonadal recrudescence and regression by environmental factors. Behav Ecol Sociobiol 4:331-355.

Kirschbaum F (1983): Myogenic electric organ precedes the neurogenic organ in apteronotid fish. Naturwissenschaften 70:305-307.

Kirschbaum F (1995): Reproduction and development in mormyriform and gymnotiform fishes; in Moller P: Electric Fishes - History and Behavior. Fish and Fisheries Series. London, Chapman \& Hall, pp 267-301.

Kirschbaum F, Schwassmann HO (2008): Ontogeny and evolution of electric organs in gymnotiform fish. J Physiol (Paris) 102:347-356.

Luft JH (1957): The histology and cytology of the electric organ of the electric eel Electrophorus electricus L. J Morphol 100:113-139.

Luft JH (1958): The fine structure of electric tissue. Exp Cell Res Suppl 5:168-182.

Machado RD, de Souza W, Cotta-Peireia G, de Oliveira-Castro G (1976): On the fine structure of the electrocyte of Electrophorus electricus L. Cell Tissue Res 174:355-366.

Machado RD, de Souza W, Benchimol M, Attias M, Porter KR (1980): Observations on the innervated face of the main organ of the electric eel (Electrophorus electricus L.). Cell Tissue Res 213:69-80.

Maunsbach A (1966): The influence of different fixatives and fixation methods on the ultrastructure of rat kidney proximal tubule cells. I. Comparison of different perfusion fixation methods and of glutaraldehyde, formaldehyde and osmium tetroxide fixatives. J Ultrastruct Res 15:242-282.

McDowell EM, Trump BF (1976): Histologic fixatives suitable for diagnostic light and electron microscopy. Arch Pathol Lab Med 100:405414.
Mills A, Zakon HH, Marchaterre AM, Bass AH (1992): Electric organ morphology of Sternopygus macrurus. J Neurobiol 23:920-932.

Nijssen H, Isbrücker IJH (1972): On Hypopygus lepturus, a little known dwarf gymnotid fish from South America (Pisces, Cypriniformes, Gymnotoidei). Zool Mededel 47:160-176.

Sachs C (1881): Untersuchungen am Zitteraal Gymnotus electricus. Leipzig, Veit, p 304.

Schwassmann HO (1984): Species of Steatogenys Boulenger (Pisces, Gymnotiformes, Hypopomidae). Bol Mus Paraense E Goeldi Zool 1:97-114

Schwassmann HO (1989): Gymnorhamphichthys rosamariae, a new species of knifefish (Rhamphichthyidae, Gymnotiformes) from the Upper Rio Negro, Brazil. Stud Neotr Fauna Environ 24:157-167.

Schwassmann HO, Assunção MIS (1989): Electric organ activity in early larval stages of poraquê Electrophorus electricus. Bol Mus Paraense E Goeldi Zool 5:143-150.

- Spurr AR (1969): A low-viscosity epoxy resin embedding medium for electron microscopy. J Ultrastruct Res 25:31-43.

Szabo T (1966): The origin of the electric organs of Electrophorus electricus. Anat Rec 155:103110 .

-Unguez GA, Zakon HH (2002): Skeletal muscle transformation into electric organ in S. macrurus depends on innervation. J Neurobiol 53:391-402.

Valentin G (1842): Beiträge zur Anatomie des Zitteraals (Gymnotus electricus). Neue Denkschr Allg Schweiz Ges Ges Naturwiss 6:3-74.

Wachtel AW (1964): The ultrastructural relationships of electric organs and muscle. I. Filamentous systems. J Morphol 114:325-360.

Yamada E (1955): The fine structure of the gall bladder epithelium of the mouse. J Biophys Biochem Cytol 1:445-458.

Zakon HH, Unguez GA (1999): Development and regeneration of the electric organ. J Exp Biol 202:1427-1434. 